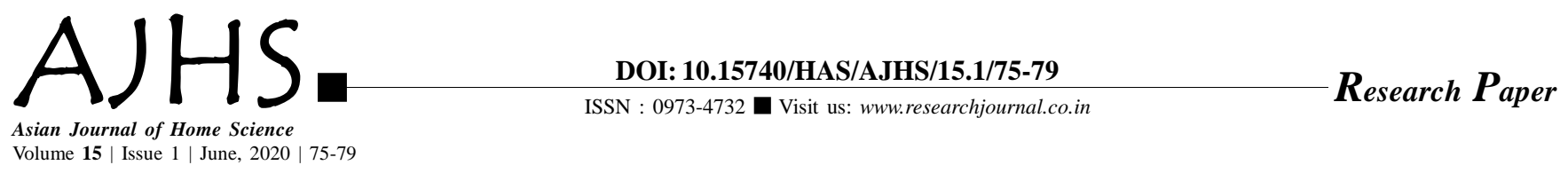

\title{
Dimensions and availability of light in bathroom and water closets
}

\author{
Meghna S. Kelgeri and Rajeshwari M. Desai
}

Received: 20.01.2020; Revised: 15.03.2020; Accepted: 30.04 .2020

See end of the paper for authors' affiliations Meghna S. Kelgeri

AICRP-H.Sc. (Family Resource Management), Main Agricultural Research Station, University of Agricultural Sciences, Dharwad (Karnataka) India

Email : meguachuth10@gmail. com
ABSTRACT : Home is the one where we spend our valuable time with family, hence the special features with regard to interior should be taken into consideration especially for the elderly people. The present study was conducted during the year 2017-2018, in urban areas of Dharwad district, Karnataka, India. The sample consisted of 120 elderly population aged 60 years and above. Exploratory research design and self structured interview schedule were used to conduct the study. In houses of majority of male and female respondents, separate bathroom and water closets were present. The size of maximum number of bathroom and water closets were bigger than the standard recommended. It was good to know that none of the bathroom and water closets were smaller than the standard recommended. The availability of natural light in maximum number of bathroom and water closets was more than the standard recommended by the BIS. But the reverse trend was observed with respect to availability of artificial light, which disclose that the intensity of artificial light in maximum number of bathroom and water closets was less than the standard recommended.

KEY WORDS: Existing housing conditions, Bathroom, Water closets, Elderly

- HOW TO CITE THIS PAPER : Kelgeri, Meghna S. and Desai, Rajeshwari M. (2020). Dimensions and availability of light in bathroom and water closets. Asian J. Home Sci., 15 (1) : 75-79, DOI: 10.15740/HAS/ AJHS/15.1/75-79. Copyright@ 2020: Hind Agri-Horticultural Society. 